\title{
Láser: ¿depilar o sacar pelo?
}

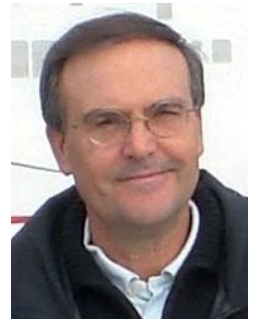

Lorenzo J. Pérez García Jefe del Servicio de Dermatología. Hospital General Universitario de Albacete.

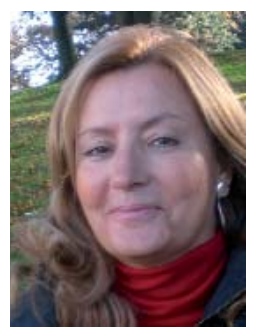

Ángela D. Sánchez Gracia

Catedrática de Física y Química.

Instituto de Enseñanza Secundaria Bachiller Sabuco. Albacete.

\section{INTRODUCCIÓN}

La palabra «láser» proviene del inglés y es un acrónimo de light amplification by stimulated emission of radiation. Se trata de un dispositivo que utiliza uno de los efectos de la mecánica cuántica, concretamente la emisión inducida o estimulada de fotones para generar un haz de luz coherente ${ }^{1}$. En dermatología, el primer usuario del que existe referencia es el doctor Goldman que, en los años sesenta, utilizó un láser rubí para tratar un tatuaje ${ }^{2}$. En esa misma década, el húngaro Mester comunicó la inducción de pelo en animales mediante tratamiento con láser³. Hasta 1998 no aparece la primera información del grupo de Anderson notificando el uso del láser para depilar ${ }^{4}$.

\section{LÁSER: PRINCIPIOS FÍSICOS ${ }^{1}$}

Los átomos poseen electrones distribuidos en diferentes niveles de energía, que buscan la situación más estable o de menor energía. Los átomos son susceptibles de absorber energía cuando sobre ellos incide una determinada radiación electromagnética.

Einstein estableció tres posibles mecanismos que tienen lugar cuando interaccionan la materia y los fotones: absorción, emisión espontánea y emisión estimulada. Cuando un fotón es absorbido por el electrón de un átomo, induce el paso del electrón a un nivel superior de energía (estado excitado); posteriormente, el electrón tiende a pasar al estado inicial devolviendo la energía absorbida mediante emisión espontánea (fig. 1). La emi-

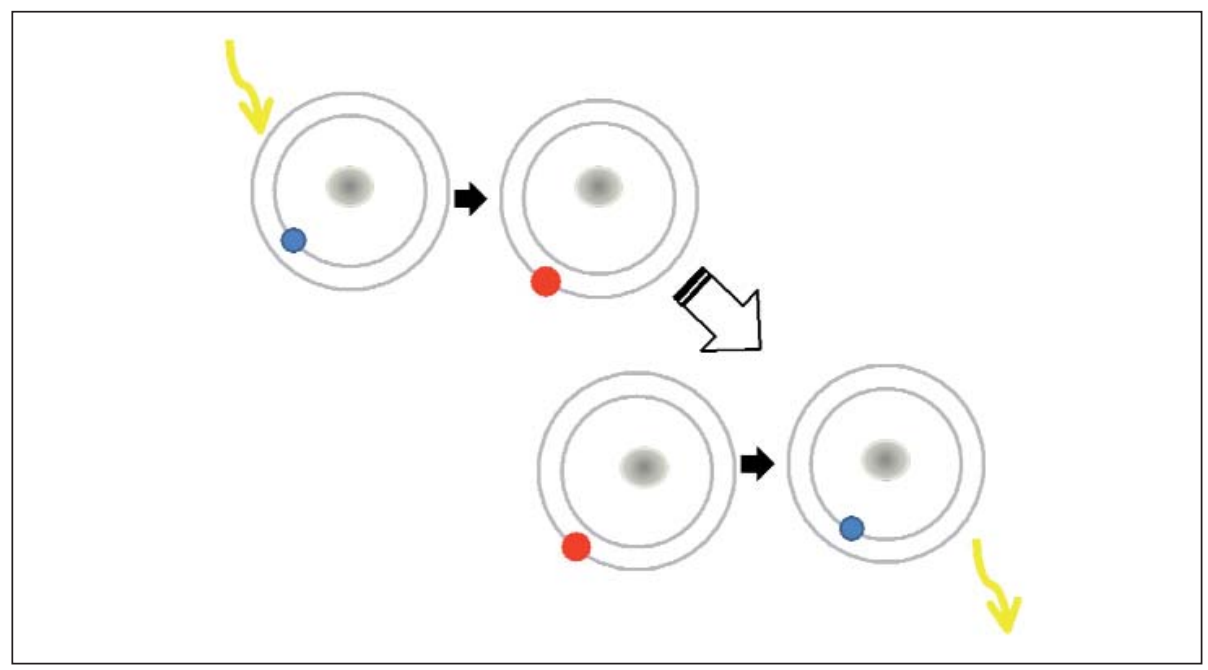

Figura 1. Cuando un fotón es absorbido por un electrón de un átomo, induce el paso del electrón a un nivel superior de energía (estado excitado); posteriormente, el electrón tiende a pasar al estado inicial, devolviendo la energía absorbida mediante emisión espontánea. 
sión estimulada se produce cuando un electrón excitado es estimulado de nuevo mediante un fotón de determinada frecuencia; en estas circunstancias, tenderá a recuperar el estado de mínima energía más rápidamente, liberando dos fotones de idéntica energía y en consonancia de fase con el incidente, por lo que la luz se amplifica (fig. 2). Estos fotones podrán a su vez estimular a otros electrones.

Einstein mostró que la probabilidad de que el fotón sea absorbido por el átomo situado en el nivel de mínima energía es igual a la probabilidad de que dicho fotón provoque la emisión estimulada en el átomo excitado. ¿Cómo conseguir que aumente la posibilidad de que el fotón sea absorbido por el átomo excitado? Todo depende de la cantidad de átomos que haya en cada nivel. Si es mayor la cantidad de átomos excitados, entonces más a menudo se producirá la emisión estimulada y el rayo de luz se intensificará. Por lo tanto, para que el haz se intensifique, es necesario crear una situación de inversión de la población, es decir, que la mayoría de los átomos estén excitados.

El láser consta de un sistema para bombear energía, un material que estimular, un medio reflectante y un emisor de la onda.

¿Cómo funciona un láser? Los átomos de una muestra sólida, líquida o gaseosa son excitados por una fuente de energía externa. Las emisiones espontáneas compiten con las estimuladas pero, cuando la mayoría de los átomos están excitados, predomina el proceso de emisión estimulada, ya que la probabilidad de que interaccione un fotón con un átomo excitado es mayor, pues son más numerosos. Si, en estas circunstancias, los fotones emitidos escaparan, la muestra volvería a un estado estable. Para evitar esto y mantener la inversión de la población de un modo continuo, la muestra se sitúa en un recipiente cerrado que tiene dos espejos reflectantes en los extremos y un orificio por donde sale la luz emitida. La fuente de energía externa mantiene la inversión de la población. Los fotones emitidos por los átomos en algunos casos emergen por las facetas del recipiente, pero en su mayor parte salen en dirección paralela al eje del recipiente y, al ser reflejados múltiples veces, actúan de estimulantes de la radiación, produciendo una reacción en cascada que sale a través del orificio y da lugar al rayo láser. El láser no es sólo un haz de radiación amplificada, además, esta radiación posee unas propiedades de coherencia, monocromaticidad y direccionalidad que la hacen realmente única y justifican la enorme variedad de sus aplicaciones.

\section{INTERACCIÓN LÁSER-TEJIDOS}

La luz sólo puede tener efectos orgánicos si es absorbida por el tejido, se convierte en energía y provoca cambios bioquímicos.

Existen diversos factores que influyen en la actuación biológica de los láser, entre ellos destacamos el tiempo de actuación y la longitud de onda, que

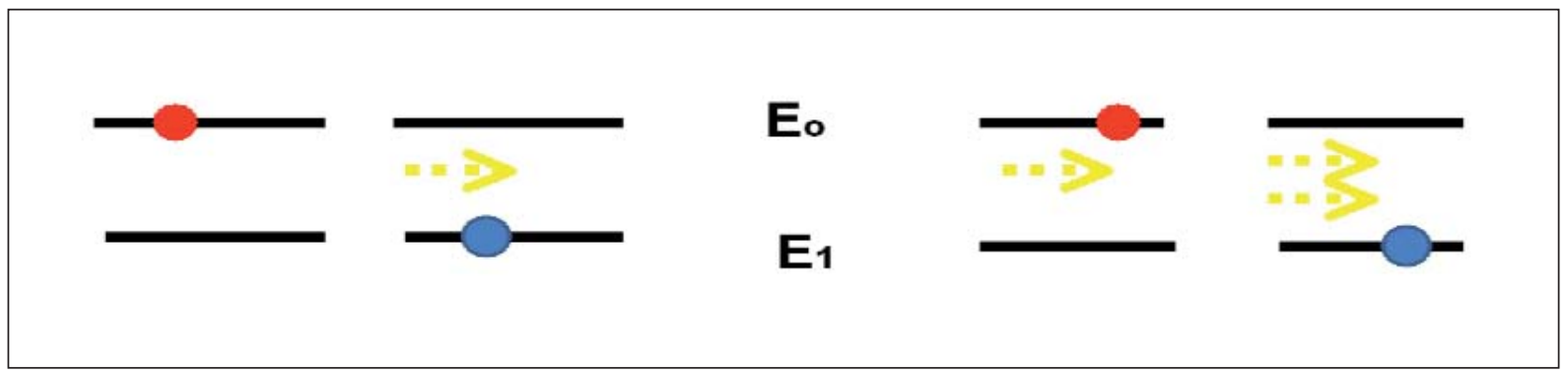

Figura 2. La emisión estimulada se produce cuando un electrón excitado es estimulado de nuevo mediante un fotón de determinada frecuencia; en estas circunstancias, tenderá a recuperar el estado de mínima energía más rápidamente, liberando dos fotones de idéntica energía y en consonancia de fase con el incidente, por lo que la luz se amplifica. 
interviene en la penetración óptica de la radiación y en la selección del cromóforo o estructura diana.

El efecto térmico es el más utilizado en los tratamientos con láser. La emisión láser produce el calentamiento de la estructura diana; si actúa de manera prolongada, el calor se transmite a los tejidos adyacentes al cromóforo y produce un daño añadido. Si queremos actuar exclusivamente en una determinada zona, tenemos que conseguir una intensidad de calor suficiente, pero limitada en el tiempo, para actuar en el cromóforo sin dañar los tejidos de alrededor.

El concepto de «fototermólisis selectiva $»^{5}$ es aquel por el cual una estructura o cromóforo determinado puede ser destruido selectivamente, reduciendo al máximo el efecto sobre las estructuras vecinas. Se basa en el «tiempo de relajación térmica» de la estructura que se quiere eliminar, que debe ser superior al tiempo de emisión de la luz utilizada. El tiempo de relajación térmica se define como el necesario para reducir al $50 \%$ la temperatura máxima obtenida en la estructura que se trata $^{6}$.

La «teoría extendida de la fototermólisis selectiva» nos permite explicar el efecto que se produce sobre las estructuras que no actúan como cromóforos y que son dañadas mediante la propagación del calor que se difunde desde la diana. Se define como «tiempo de daño térmico» el necesario para producir el calentamiento del cromóforo y de la estructura adyacente.

Los láseres de baja energía ejercen su efecto biológico aumentando la cantidad de adenosín trifosfato (ATP) producido por las mitocondrias; existen evidencias de que aumenta la actividad de los complejos II y IV de la cadena respiratoria mitocondrial $^{7}$.

\section{LÁSER: DEPILAR}

El uso para depilar no se inició hasta la aparición de la teoría de la fototermólisis selectiva formulada por Anderson y Parrish ${ }^{5}$, que permite explicar el mecanismo de la fotodepilación. Aunque la absorción de energía se efectúa fundamentalmente en la melanina del bulbo, conseguimos afectar también a la papila dérmica y las células de la protuberancia del folículo piloso ${ }^{6}$. Para conseguir una eliminación permanente del vello, la diana biológica son las células madre situadas en esas localizaciones ${ }^{8}$.

La técnica de la depilación por láser es eficaz cuando empleamos los parámetros óptimos para el tratamiento, la destrucción de células madre es completa y conseguimos la eliminación definitiva del vello.

Además de los aparatos utilizados (que condicionan la longitud de onda emitida), en la eficacia de la depilación influye la densidad de energía aplicada en el tejido (julios $/ \mathrm{cm}^{2}$ ), la duración del pulso (tiempo en segundos de exposición al láser) y la extensión de la zona donde aplicamos el láser. La cantidad de energía aplicada por unidad de superficie debe ser la máxima que el paciente tolere sin tener efectos secundarios y precisa ser ponderada por el aplicador. La duración idónea del pulso está condicionada por la teoría de la termólisis selectiva y la teoría ampliada de la termólisis selectiva aplicada al pelo, por tanto, se debe considerar el tiempo de relajación térmica y la distancia del cromóforo al objetivo biológico. La extensión del disparo (spot) debe ser la mayor posible, ya que los fotones tienden a dispersarse más de la diana cuanto menor sea el tamaño del spoty, además, conseguiremos cubrir el área tratada en menos tiempo.

Se considera que un tratamiento de depilación es eficaz cuando conseguimos eliminar el 15-30\% de los folículos ${ }^{9}$. Existen estudios, numerosos y bien contrastados, que prueban la eficacia de los láseres en este sentido ${ }^{10}$.

\section{LÁSER: SACAR PELO}

Paradójicamente, existen informaciones que apuntan en sentido contrario, las ondas lumínicas pueden favorecer el desarrollo del pelo. Es bien conocido el uso del PUVA en la alopecia areata universal para estimular el crecimiento del pelo. Existen informes de inducción de pelo en animales tras 
aplicación de láser ${ }^{3}$. Hay constancia de aparición de vello en áreas tratadas con láseres empleados para tratar el nevus flameus y para eliminación de tatuajes ${ }^{11}$. Está profusamente documentado el fenómeno de la «hipertricosis paradójica» (inducción de pelo terminal en mejillas y barbilla) tras depilación por láser en la zona de la cara, que es relativamente frecuente en las mujeres mediterráneas ${ }^{6}$.

El láser de baja potencia, que puede mejorar la cicatrización de las heridas, reducir la inflamación y acelerar la recuperación tisular en accidentes cerebrovasculares ${ }^{12}$, también puede estimular el crecimiento del cabello ${ }^{3}$; existen a este respecto estudios sobre el tratamiento de la alopecia androgénica en varones ${ }^{13}$ que apoyan estas afirmaciones.

¿Cuál es la base teórica de esta actuación? La activación de la cadena respiratoria mitocondrial que interviene en la producción de $\mathrm{ATP}^{7}$ puede ser la razón, pero no deja de ser una especulación y realmente no se conoce bien cómo el ATP interviene en el pelo. Hacen falta trabajos independientes que estudien y demuestren el papel de los láseres de baja potencia en el estímulo del crecimiento y mantenimiento del pelo; en ese sentido, destacamos la reciente aparición de un trabajo en ratones tratados con láser de helio-neón ${ }^{14}$.

\section{LÁSER DE USO DOMICILIARIO}

Recientemente, están apareciendo láseres de uso domiciliario $^{15}$, tanto para depilación como para estimulación capilar. Grandes compañías productoras de láser están llegando a alianzas con empresas de cosméticos y gran consumo para desarrollar nuevos sistemas dermoestéticos.

Los láseres de uso domiciliario ofrecen unos rangos de potencia menores que los de uso profesional, consiguen mayores fluencias, suministradas con tiempos de pulsos más prolongados, con lo cual tienen dificultades teóricas para realizar la depilación según los criterios de la fototermólisis ampliada.

Los dispositivos de uso domiciliario destinados al estímulo capilar también tienen un peso impor- tante en este mercado y pueden, teóricamente, conseguir mejor sus objetivos, ya que precisan menores potencias para actuar. Son necesarios estudios controlados poscomercialización para establecer tanto la eficacia como la seguridad de estos aparatos.

\section{BIBLIOGRAFÍA}

1. Requena A, Zúñiga J. Espectroscopía. 1a ed. Madrid: Ed. Prentice Hall; 2004.

2. Goldman L, Wilson RG, Hornby P, Meyer RG. Radiation from a Q-switched ruby laser: effect of repeated impacts of power output of 10 megawatts on a tattoo of man. J Invest Dermatol. 1964;44:69-71.

3. Mester E, Szende B, Gartner P. The effect of laser beams on the growth of hair in mice. Radiobiol Radiother. 1968;9: 621-6.

4. Dierickx CC, Grossman MC, Farinelli WA, Anderson RR. Permanent hair removal by normal-mode ruby laser. Arch Dermatol. 1998:134(7):837-42.

5. Anderson RR, Parrish JA. Selective photothermolysis: precise microsurgery by selective absorption of pulsed radiation. Science. 1983:220(4596):524-52.

6. Vélez González M, Rigau I, Mas J, Trelles MA. Fundamentos físicos de la emisión lúmínica. En: Cisneros JL, Camacho FM, Trelles MA. Láser en Dermatología y Dermocosmética. $2^{\underline{a}}$ ed. Madrid: Aula Médica; 2008. p. 49-64.

7. Oron U, llic S, DeTaboada L, Streeter J. Ga-As (808-nm) laser irradation enhances ATP production in human neuronal cells in culture. Photomed Laser Surg. 2007;25:180-2.

8. Altshuler GB, Anderson RR, Manstein D, Zenzie HH, Smirnov MZ. Extended theory of selective photothermolysis. Lasers Surg Med. 2001:29(5):416-32.

9. Grossman MC. Long term comparison of different lasers and light sources for hair removal. Lasers SurgMed. 2000: 12(Suppl.):89.

10. Ibrahimi A, Avram M, Hanke C, Kilmer S, Anderson R. Laser hair removal. Dermatol Ther. 2011;24:94-107.

11. Vlachos SP, Kontoes PP. Development of terminal hair following skin lesion treatments with an intense pulsed light source. Aesth Plast Surg. 2002;26:303-7.

12. Lampl Y, Zivin JA, Fisher M, Lew R, Welin L, Dahlof B, et al. Infrared laser therapy for ischemic stroke: a new treatment strategy: results of the Neurothera Effectiveness and Safety Trial-1 (NEST-1). Stroke. 2007;38:1843-9.

13. Leavitt M, Charles G, Heyman E, Michaels D. HairMax LaserComb laser phototherapy device in the treatment of male androgenetic alopecia: a randomized double-blind, sham device-controlled, multicentre trial. Clin Drug Investig. 2009;29: 283-92.

14. Shukla S, Sahu K, Verma Y, Rao KD, Dube A, Gupta PK. Effect of helium-neon laser irradiation on hair follicle growth cycle of swiss albino mice. Skin Pharmacol Physiol. 2010;23:79-85.

15. López-Estebaranz JL, Cuerda E. Dispositivos médico-estéticos de uso domiciliario: presente y futuro. Actas Dermosifiliogr. 2010;101(3):223-9. 